\title{
RETRACTED ARTICLE: Unpacking the employee responses to ethical leadership: The role of collective moral emotion
}

\section{Zhe Zhang $\cdot$ Ming Jia}

Published online: 6 November 2013

(C) Springer Science+Business Media New York 2013

This article has been retracted by the Publisher due to plagiarism.

This article has been retracted by the Publisher due to plagiarism.

\section{Z. Zhang}

School of Management, Xi'an Jiaotong University, Xi'an, Shannxi 710049, China e-mail: zhangzhe220@sina.com

M. Jia $(\bowtie)$

School of Management, Northwestern Polytechnical University, Xi'an, China

e-mail: mingazhe@sina.com 